\title{
José Guilherme Jordão - Uma vida e uma obra para o futuro
}

Manuel Valente Alves*

osé Guilherme Jordão (1951-2003) foi um dos grandes protagonistas da história da Medicina Geral e Familiar (MGF) em Portugal. Ele insere-se numa genealogia de médicos que souberam promover os aspectos preventivos e curativos e da doença, o ensino e a investigação médica, numa perspectiva integrada, perfilhando alguns dos principais valores que impregnam a matriz da MGF. Entre estes médicos, podemos referir, a título de exemplo, Tomás de Sousa Martins (1843-1897) ${ }^{1: 253}$ e Carlos Bello Moraes (1868-1933), duas figuras maiores da medicina que se destacaram entre a segunda metade do século XIX e o começo do século XX. De referir igualmente Fernando Fonseca (1895-1974), figura cimeira da medicina em Portugal na primeira metade do século XX, considerado por Reynaldo dos Santos como uma das figuras mais prestigiadas do clínico geral da época, ${ }^{1: 285}$ cujo perfil se coaduna perfeitamente com a moderna MGF. Todos eles foram líderes discretos, mas eficazes, que introduziram precocemente mudanças no ensino e na prática da medicina que se reflectiram positivamente na evolução da saúde em Portugal. A sua vasta cultura científica e humanista, que lhes permitiu renovarem a tradição hipocrática da medicina entre nós, tornaram-nos precursores da MGF.

Tive o privilégio de trabalhar pessoalmente com Guilherme Jordão em 1999, quando dirigi o livro-catálogo 1911-1999-O ensino médico em Lisboa no início do século: sete artistas contemporâneos evocam a geração médica de 1911, no contexto da exposição com o mesmo nome, de que fui comissário, na Fundação Calouste Gulbenkian, em Lisboa, no âmbito do IX Congresso de Educação Médica. Convidei-o para colaborar no livro com um ensaio sobre a vida e a obra de Bello Moraes, um dos professores retratados nas quatro magníficas te-

* Médico de família na USF Sofia Abecassis, ACES Lisboa Central e investigador universitário. Foi regente da disciplina de História da Medicina na Faculdade de Medicina da Universidade de Lisboa. Fundou e dirigiu o Museu de Medicina da Universidade de Lisboa. É membro da Academia Nacional de Medicina de Portugal. las que Columbano Bordalo Pinheiro pintou em 1906 para o edifício da Escola Médico-Cirúrgica de Lisboa e que actualmente fazem parte da colecção do Museu de Medicina da Universidade de Lisboa. Aceitou o convite de braços abertos. Guilherme Jordão confessa que, "no avançar progressivo da descoberta" da vida e da obra de Bello Moraes, ele próprio "foi precocemente condicionado pela perspectiva determinada pelos seus próprios valores pessoais e profissionais, relacionados com o exercício da Medicina Geral e Familiar". 2:178 Em Bello Moraes, esclarece Guilherme Jordão, "ressalta a clínica tendo como referência os aspectos biológicos, psicológicos e sociais; é evidente a globalização na abordagem dos problemas de saúde; há claramente uma valorização da componente familiar nessa intervenção; existe uma valorização das actividades de ensino e de investigação como estratégias de desenvolvimento; existe um saber transversal e multidisciplinar facilitador da resolução de problemas; está permanentemente patente a preocupação com os aspectos éticos e deontológicos do exercício médico; revela-se a cultura do respeito e da amizade como valores essenciais para a dignificação dos médicos como corpo profissional com particular responsabilidade social." ${ }^{2}$ Conclui: "Em suma, Bello Moraes reuniu atributos que hoje são importantes referências para projectos de intervenção global, como acontece no âmbito da Medicina Geral e Familiar."2

Em 2003, no contexto do projecto 'Cadernos de Viagem', comemorativo dos 20 anos da Associação Portuguesa de Médicos de Clínica Geral (APMCG), eu e Vítor Ramos, na qualidade de responsáveis pela concepção e execução do projecto, convidámo-lo a escrever para o livro Da Vontade. Guilherme Jordão aceitou com gosto escrever sobre dois temas que lhe eram muito gratos: a história dos Institutos de Clínica Geral e o trajecto percorrido pela MGF académica em Portugal no curto período que decorre desde o seu nascimento, no começo da década de 1980, até 2003. Conclui este último 
texto realçando o muito que foi feito em tão pouco tempo e as boas perspectivas de futuro: "atendendo aos factos apontados ocorridos em tempo relativamente curto e considerando a dimensão do projecto e da obra levada a cabo, pode-se afirmar que muito foi realizado no domínio do ensino pré-graduado da MGF em Portugal e que estão criados os espaços de debate e de reflexão determinantes para a sua evolução como disciplina académica, especialidade e área organizada de prestação de cuidados de saúde." ${ }^{\text {3:77 }}$

Guilherme Jordão contribuiu, através da sua ampla cultura científica e humanista, para a afirmação da MGF quer como especialidade quer como disciplina académica. Fê-lo com uma visão estratégica e um sentido de missão assinaláveis. Num curto período de tempo percebeu que, para vencer os inúmeros escolhos que dificultavam o avanço da MGF, era preciso uma liderança forte que definisse uma ideia, um rumo e que, para manter esse rumo, era preciso criar instituições robustas, como a APMCG, que defendessem não apenas a qualidade científica do exercício profissional, mas também a formação pré e pós-graduada e valorizassem os aspectos socioprofissionais ligados à especialidade. Por isso, Guilherme Jordão trabalhou simultaneamente em várias frentes, com um vigor e uma tenacidade excepcionais. Apesar da sua curta vida, morreu com 52 anos, o seu currículo, centrado na MGF, é vasto e rico. Participou na organização do $1 .^{\circ}$ Internato Complementar de Clínica Geral, tendo sido eleito representante do Grupo de Internos de Clínica Geral da Zona Sul. Foi assessor do secretário de Estado da Saúde, Paulo Mendo, entre 1981 e 1983. Ainda interno, contribuiu na elaboração do primeiro regulamento dos Centros de Saúde. Entre 1983 e 1984 tornou-se especialista de Clínica Geral pela Ordem dos Médicos. Desde a sua fundação, colaborou estreitamente com a APMCG, mais tarde Associação Portuguesa de Medicina Geral e Familiar. A sua actividade clínica e de ensino, pré e pós-graduado, foi intensa. Trabalhou na reestruturação do ensino médico, exerceu as funções de coordenador de Internato de Clínica Geral da Zona Sul, de director do Instituto de Clínica Geral da Zona Sul e foi membro da Comissão Internacional de Revisão do Ensino Médico, defendendo o sexto ano pré-graduado profissionalizante. Em 1993 doutorou-se em medicina com a tese A Medicina Geral e Familiar - Caracteriza-

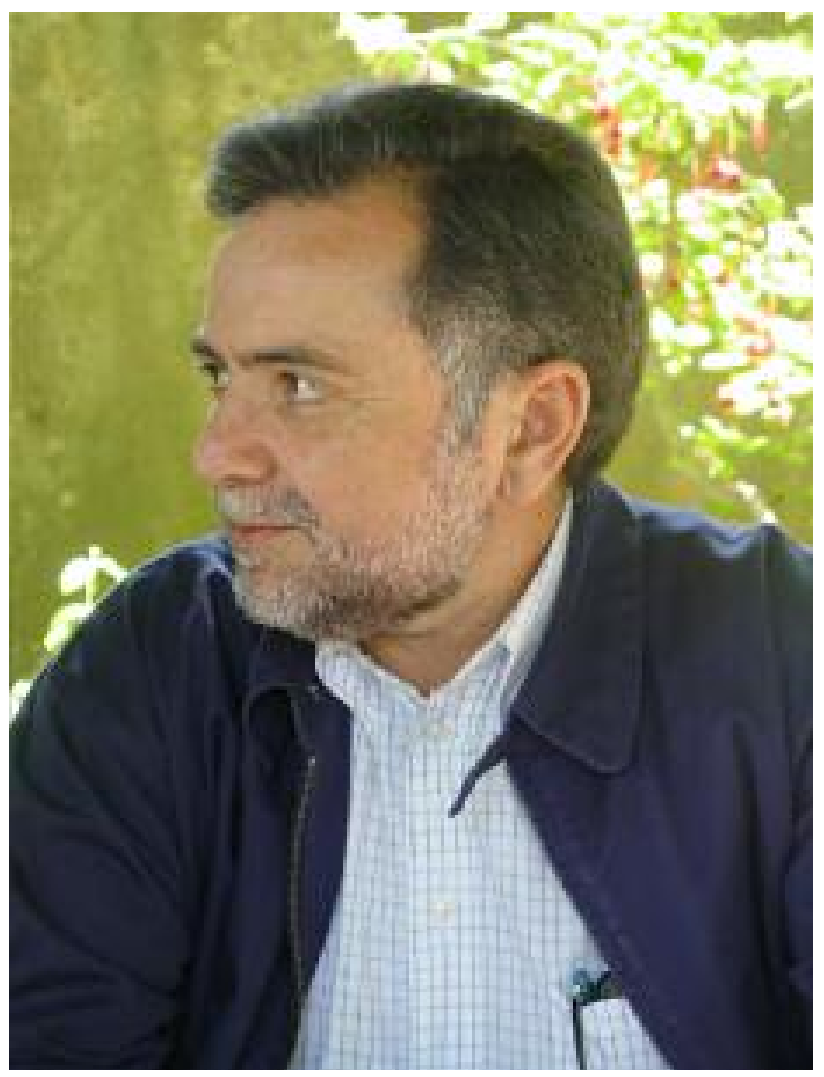

José Guilherme Jordão (2003).

Foto: Nina Szielasko.

ção da sua prática e influência no ensino pré-graduado, tornando-se uma presença regular nos círculos académicos associados à formação pré e pós-graduada. Em 1996 ingressou no Departamento de Educação Médica da Faculdade de Medicina da Universidade de Lisboa, sendo professor auxiliar convidado e regente de Clínica Geral e Medicina Comunitária. Foi mestre em Educação Médica, diplomado em Educação Médica pelo College of Medicine da Universidade de Wales e membro da direcção da Sociedade de Ciências Médicas de Lisboa e da Sociedade Portuguesa de Educação Médica, onde pertenceu à sua direcção em três mandatos consecutivos, 1997 até 2003. Aquando do seu falecimento estava integrado num projecto europeu inovador e, em colaboração com a sua amiga Madalena Patrício, mestre em Pedagogia, escreveu o livro Manual de boas práticas pedagógicas em saúde. ${ }^{4}$ Colaborou com a Revista Portuguesa de Clínica Geral e foi presidente da 
Associação de Docentes e Orientadores de Clínica Geral.

Há um traço na sua personalidade que me tocou particularmente: $\mathrm{o}$ amor pela cultura. A este propósito, recordo um almoço no restaurante do Museu do Traje, em Lisboa, comigo e com a minha mulher, a designer e fotógrafa Nina Szielasko, seguido de um passeio nos jardins do Parque do Monteiro-Mor para uma sessão de fotografias destinada a acompanhar os seus artigos para o livro Da Vontade. Nas três horas em que estivemos juntos falámos exclusivamente de arte: da pintura e da fotografia à música, ao património, à filosofia e à literatura. Guilherme Jordão possuía um gosto simples e requintado. Preferia a simplicidade e a depuração ao excesso maneirista e barroco. Quando, a propósito, recordei uma expressão atribuída a Goethe em que este pede desculpa a um amigo pela extensa carta que acabara de lhe enviar, porque não tinha tido tempo para lhe escrever uma mais curta, riu abertamente. Foi para mim uma tarde que jamais esquecerei. Junto um dos re- tratos de José Guilherme Jordão tirado na altura, de que gosto muito.

\section{REFERÊNCIAS BIBLIOGRÁFICAS}

1. Valente-Alves M. História da medicina em Portugal: origens, ligações e contextos. Porto: Porto Editora; 2014. ISBN 9789720062925

2. Jordão JG. C. Bello Moraes - Uma vida e uma obra no presente. In Valente-Alves M, editor. 1911-1999 - O ensino médico em Lisboa no início do século: sete artistas contemporâneos evocam a geração médica de 1911. Lisboa: Fundação Calouste Gulbenkian; 1999. p. 159-65. ISBN 9726780292

3. Jordão JG. A medicina geral académica e o desenvolvimento universitário da disciplina em Portugal. In Valente-Alves M, Ramos V, editors. Medicina geral e familiar: da vontade. Lisboa: MVA Invent; 2004. ISBN 97897298886183

4. Jordão JG, Patrício MF. Manual de boas práticas pedagógicas em saúde. Lisboa: Sociedade Portuguesa de Educação Médica; 2004.

\section{CONFLITO DE INTERESSES}

O autor declara não ter conflito de interesses.

ENDEREÇO PARA CORRESPONDÊNCIA

m.valentealves@gmail.com 